Document downloaded from:

http://hdl.handle.net/10251/80303

This paper must be cited as:

Gil Castell, O.; Badía Valiente, JD.; Kittikorn, T.; Strömberg, E.; Ek, M.; Karlsson, S.; Ribes Greus, MD. (2016). Impact of hydrothermal ageing on the thermal stability, morphology and viscoelastic performance of PLA/sisal biocomposites. Polymer Degradation and Stability. 132:87-96. doi:10.1016/j.polymdegradstab.2016.03.038.

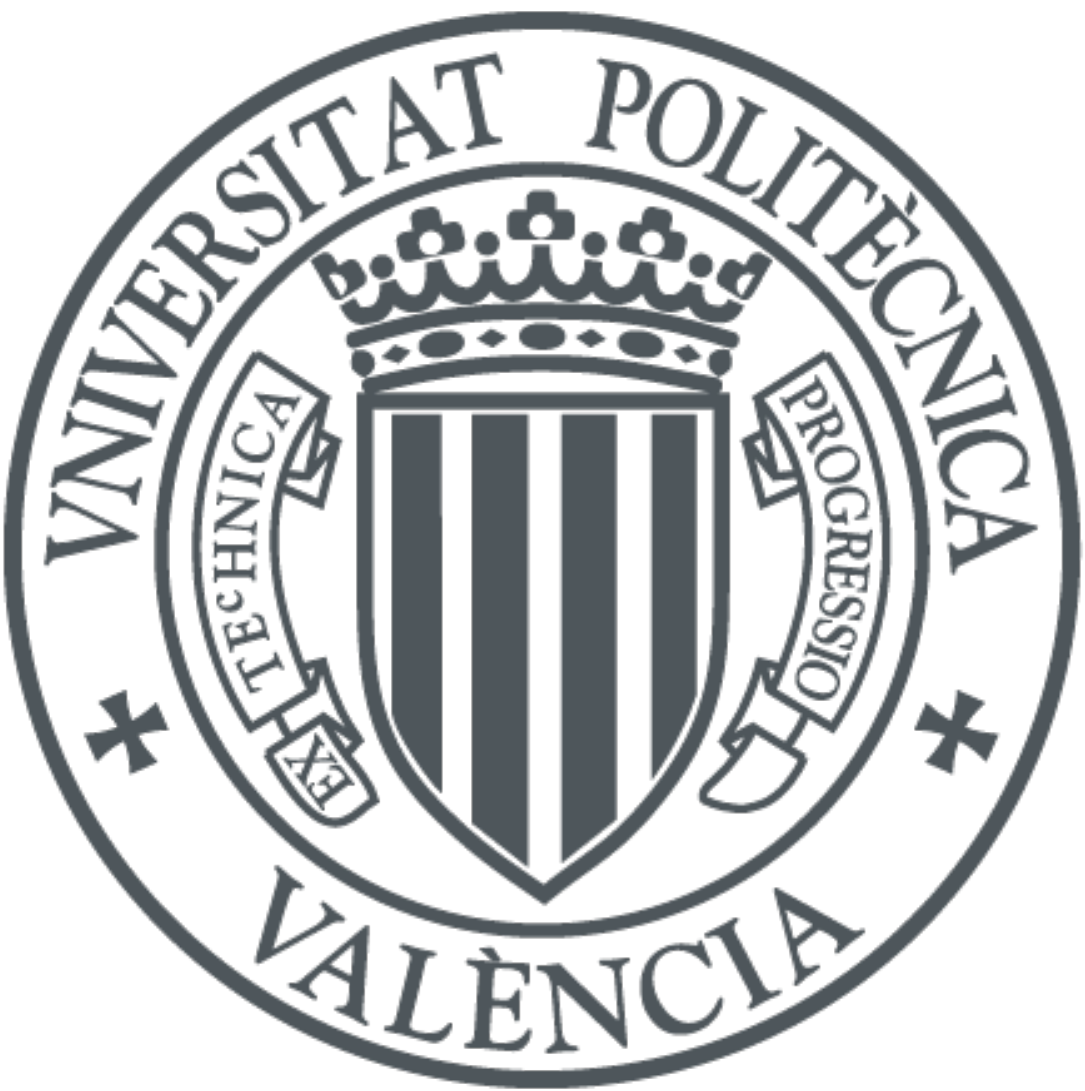

The final publication is available at

http://dx.doi.org/10.1016/j.polymdegradstab.2016.03.038

Copyright Elsevier

Additional Information 


\section{IMPACT OF HYDROTHERMAL AGEING ON THE THERMAL STABILITY, MORPHOLOGY AND VISCOELASTIC PERFORMANCE OF PLA/SISAL BIOCOMPOSITES}

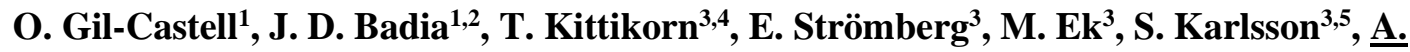 $\underline{\text { Ribes-Greus }^{1, *}}$.}

This is an open-access version, according to http://www.sherpa.ac.uk/romeo/issn/0141-3910/

Full text available at http://www.sciencedirect.com/science/article/pii/S0141391016300970

DOI: $\underline{\text { doi:10.1016/j.polymdegradstab.2016.03.038 }}$

Please, cite it as:

O. Gil-Castell, J. D. Badia, T. Kittikorn, E. Strömberg, M. Ek, S. Karlsson, A. Ribes-Greus. Impact of hydrothermal ageing on the thermal stability, morphology and viscoelastic performance of PLA/sisal biocomposites. Polymer Degradation and Stability 2016, 132; 87-96

${ }^{1}$ Instituto de Tecnología de Materiales (ITM),

Universidad Politècnica de València (UPV)

Camino de Vera S/N, 46022 Valencia, Spain.

${ }^{2}$ Departament d' Enginyeria Química.

Escola Tècnica Superior d'Enginyeria.

Universitat de València.

Av. de la Universitat, s/n, 46100, Burjassot, Spain.

${ }^{3}$ School of Chemical Science and Engineering,

Fibre and Polymer Technology,

KTH - Royal Institute of Technology,

Teknikringen 56-58, SE-10044 Stockholm, Sweden.

${ }^{4}$ Department of Materials Science and Technology,

Faculty of Science,

Prince of Songkla University.

Songkhla, 90112, Thailand.

${ }^{5}$ Skövde University,

SE-541 28 Skövde, Sweden.

*Corresponding author:

A. Ribes-Greus aribes@ter.upv.es 


\title{
IMPACT OF HYDROTHERMAL AGEING ON THE THERMAL STABILITY, MORPHOLOGY AND VISCOELASTIC PERFORMANCE OF PLA/SISAL BIOCOMPOSITES
}

\author{
O. Gil-Castell ${ }^{1}$, J. D. Badia ${ }^{1,2}$, T. Kittikorn ${ }^{3,4}$, E. Strömberg ${ }^{3}$, M. Ek ${ }^{3}$, S. Karlsson ${ }^{3,5}, \underline{\text { A. }}$ \\ $\underline{\text { Ribes-Greus }^{1, *}}$.
}

\begin{abstract}
The influence of the combined exposure to water and temperature on the behaviour of polylactide/sisal biocomposites coupled with maleic acid anhydride was assessed through accelerated hydrothermal ageing. The biocomposites were immersed in water at temperatures from 65 to $85^{\circ} \mathrm{C}$, between the glass transition and cold crystallisation of the PLA matrix. The results showed that the most influent factor for water absorption was the percentage of fibres, followed by the presence of coupling agent, whereas the effect of the temperature was not significant. Deep assessment was devoted to biocomposites subjected to hydrothermal ageing at $85^{\circ} \mathrm{C}$, since it represents the extreme degrading condition. The morphology and crystallinity of the biocomposites were evaluated by means of X-Ray diffraction (XRD) and field emission scanning electron microscopy (FE-SEM). The viscoelastic and thermal performance were assessed by means of dynamic-mechanical-thermal analysis (DMTA) and thermogravimetry (TGA). The presence of sisal generally diminished the thermal stability of the biocomposites, which was mitigated by the addition of the coupling agent. After composite preparation, the effectiveness of the sisal fibre was improved by the crystallisation of PLA around sisal, which increased the storage modulus and reduced the dampening factor. The presence of the coupling agent strengthened this effect. After hydrothermal ageing, crystallisation was promoted in all biocomposites therefore showing more fragile behaviour evidencing pores and cracks. However, the addition of coupling agent in the formulation of biocomposites contributed in all cases to minimise the effects of hydrothermal ageing.
\end{abstract}

\section{Keywords}

Biocomposites, polylactide (PLA), natural fibres, sisal, hydrothermal ageing, degradation, performance, mechanical fibre effectiveness 
O. Gil-Castell, J. D. Badia, T. Kittikorn, E. Strömberg, M. Ek, S. Karlsson, A. Ribes-Greus. Impact of hydrothermal ageing on the thermal stability, morphology and viscoelastic performance of PLA/sisal biocomposites. Polymer Degradation and Stability 2016, 132; 87-96

\section{Introduction}

Poly(lactic acid) or polylactide (PLA) is a biodegradable, highly versatile polyester produced from renewable sources [1]. It is mainly based on agricultural bases such as corn, beet, wheat and other starchy products [2]. The development of fully biodegradable composite materials based on PLA and lignocellulosic fibres is a technological challenge [3] [4] [5] [6]. Natural fibres provide better mechanical properties including high strength and stiffness without compromising important factors such as biodegradability, density or cost [7] [8] [9] [10]. Composites made of polylactide and natural fibres such as kenaf [11], hemp [7], flax [3] and sisal fibre [12] have been investigated and used in several applications. However, adverse effects can occur due to the high affinity to water of these natural fibres [13] [14] [15]. The chemical nature or surface topology may influence the composite interfacial bond [16]. In a composite, a susceptible area of degradation is the fibre-matrix interface, where decoupling, cracks and delamination can take place as a result of water absorption [17] [18]. In order to improve this interface, some alternatives have been proposed, such as coating the whole composite with a thin layer of polypropylene [19], adding an anti-hydrolysis agent [20] or even looking for specific processing methods [21] [22]. Among these, the incorporation of a coupling agent to the system is a simple and effective option to improve the cohesiveness of the composite and thus, the hydrolytic resistance [12] [22] [23] [24] [25] [26]. Usually, the addition of a coupling agent promotes chemical reactions between functional groups of the polymer matrix in their chain ends $(-\mathrm{OH},-\mathrm{COOH})$ and $-\mathrm{OH}$ groups characteristic of cellulosic natural fibres [25] [26]. Maleic anhydride (MAH) is one of the most widely used reactive couplers due to its good chemical reactivity, low toxicity and low potential to polymerize itself under free radical grafting conditions [27].

Several factors can catalyse the hydrolytic breakage of the ester bond, such as acidic conditions, high moisture or high temperatures. Previous studies have demonstrated the relative stability of PLA and natural fibre when immersed in water at temperatures below the glass transition [12] [20]. In these cases, a Fickian model seems to govern the water uptake process. Conversely, at temperatures above the glass transition high degradation rates take place and non-Fickian behaviour in water uptake have been reported [12]. A high degradation degree can be achieved when samples are subjected to high temperatures and, therefore, long-term properties can be studied after water saturation. Accelerated hydrothermal ageing tests are regarded as a suitable tool to bring the materials to an advanced state of degradation as they could be after a hypothetical hydrolytic degradation along their service life [12] [28] [29] [30].

This research was focused on the influence of combined water and temperature on the morphology, thermal and viscoelastic performance of polylactide/sisal biocomposites, with special interest on the effects of using coupling agent in the formulation of the biocomposites.

\section{Experimental procedure}

\subsection{Materials and reagents}

Polylactide (PLA) 3251D was purchased from Natureworks (Minnetonka, USA) as pellets, with a glass transition in the $65-70{ }^{\circ} \mathrm{C}$ range. Sisal fibres coming from a farming crop, were supplied by the Thai Royal Project [31]. Their length was about $0.5-1 \mathrm{~mm}$, tensile strength of $550 \mathrm{MPa}$, tensile modulus of $30 \mathrm{GPa}$ and density about $1.5 \mathrm{~g} \cdot \mathrm{cm}^{-3}$. Dicumyl peroxide (DCP) $98 \%$ (SigmaAldrich, Sweden AB) and maleic anhydride (MAH) M188-99\% (Sigma-Aldrich, Sweden AB) were used as free radical initiator and coupling agent, respectively. 
O. Gil-Castell, J. D. Badia, T. Kittikorn, E. Strömberg, M. Ek, S. Karlsson, A. Ribes-Greus. Impact of hydrothermal ageing on the thermal stability, morphology and viscoelastic performance of PLA/sisal biocomposites. Polymer Degradation and Stability 2016, 132; 87-96

\subsection{Sample preparation}

Prior to processing, virgin PLA (VPLA) and sisal fibre were dried in an oven at $80{ }^{\circ} \mathrm{C}$ during at least 12 hours and kept in zip bags. The fibre contents in the biocomposite were formulated as $10 \%, 20 \%$ and $30 \%$ by weight with and without coupling agent. In case of not using MAH, composites were prepared in an internal mixer (Brabender, Germany) during 5 minutes at $180{ }^{\circ} \mathrm{C}$ at the speed of $50 \mathrm{rpm}$. The resulting biocomposites were labelled as PLA10, PLA20 and PLA30. Biocomposites containing the coupling agent were prepared by incorporating $\mathrm{MAH} 2.5 \%$ and DCP $0.3 \%$ by weight in molten polymer and mixing during 5 minutes at $180{ }^{\circ} \mathrm{C}$ at the speed of $50 \mathrm{rpm}$. These samples were labelled as PLA10C, PLA20C and PLA30C. The compounded PLA/sisal biocomposite was then ground and the granules dried at $80^{\circ} \mathrm{C}$ in the oven during at least $12 \mathrm{~h}$. The final samples were obtained by means of a compression moulding equipment (Fontijne Presses, Netherlands). The biocomposites preparation procedure consisted of preheating the press to $200{ }^{\circ} \mathrm{C}$ for $2 \mathrm{~min}$ and applying a compression force of $150 \mathrm{kN}$ during $2 \mathrm{~min}$. An automatic cooling procedure into the press was performed. All the compression moulding operations were performed under vacuum conditions. The thickness of the sheet-shaped samples was $0.5 \pm 0.1 \mathrm{~mm}$. Finally, all compounded biocomposites were dried at $50{ }^{\circ} \mathrm{C}$ in a vacuum oven (Heraeus Vacutherm 6025, Germany), then kept in zip bags and placed in a desiccator for further analyses at normalized lab conditions according to ISO 291 [32].

\subsection{Hydrothermal ageing procedure}

A normalized water absorption test reported in the ISO 62 - method 1 [33] was adopted as hydrothermal ageing environment. Temperature specifications were adapted to the desired ageing conditions. Samples of VPLA and composites were submerged into distilled water at six different temperatures $\left(60,65,70,75,80\right.$ and $\left.85^{\circ} \mathrm{C}\right)$, below and above the polymer glass transition $(\sim 70$ $\left.{ }^{\circ} \mathrm{C}\right)$ and below the cold-crystallisation $\left(\sim 105^{\circ} \mathrm{C}\right)[12]$, until water saturation was reached. In order to establish a common criterion, for a given temperature, the test extent was considered as the triple of the saturation time for the material with slower saturation rate, in order to assure that the mass uptake profiles followed an asymptotic horizontal behaviour, meaning the completion of the saturation. Concretely 8.0, 6.9, 3.3, 3.1, 2.5 and 2.3 hours were considered for the assays performed at $60,65,70,75,80$ and $85^{\circ} \mathrm{C}$, respectively.

\subsection{Characterisation}

\subsubsection{Water uptake}

After saturation of biocomposites by water, the specimens were gently wiped to get rid of surface moieties. The amount of absorbed water $\left(M_{S}\right)$ was calculated according to the Equation 1, where $m_{S}$ and $m_{0}$ are the saturation mass and initial mass of the specimens, respectively. A weight difference procedure by means of a scale (Mettler Toledo AB135-S) with a precision of $0.1 \mathrm{mg}$ was implemented. The average of quintuplicates was considered as a representative value.

$$
M_{S}=\frac{m_{S}-m_{0}}{m_{0}} \times 100 \quad(\text { Equation 1) }
$$

\subsection{2. $X$-Ray diffraction $(X R D)$}

An X-Ray diffraction instrument (X'Pert Pro diffractometer model PW3040/60) was used to determine the crystal size of the biocomposites. Dried specimens of $100 \mathrm{~mm}^{2}$ were considered for the analysis. The $\mathrm{Cu} \mathrm{K} \alpha$ radiation $(\lambda=1.5418 \AA)$ was generated with a tension of $45 \mathrm{kV}$ and 
O. Gil-Castell, J. D. Badia, T. Kittikorn, E. Strömberg, M. Ek, S. Karlsson, A. Ribes-Greus. Impact of hydrothermal ageing on the thermal stability, morphology and viscoelastic performance of PLA/sisal biocomposites. Polymer Degradation and Stability 2016, 132; 87-96

current of $35 \mathrm{~mA}$ and then monochromatized by using a Ni filter of $20 \mu \mathrm{m}$. The experiment was measured and recorded in a reflection mode at the angular range of 5-60 $(2 \theta)$ and a rate of scanning of $0.05^{\circ}$ per $10 \mathrm{~s}$. An average spectrum of three different specimens was considered as representative for each sample.

In order to determine the mean size of the crystalline domains, the Scherrer's equation was exploited (Equation 2), where $K$ is a dimensionless shape factor (0.9), $\lambda$ is the $\mathrm{X}$-Ray wavelength $(0.154 \mathrm{~nm}), \beta$ is the line broadening at half the maximum intensity after subtracting the instrumental line broadening in radians and $\theta$ is the Bragg angle. The peak of $16.8^{\circ}(2 \theta)$ was observed to calculate the crystal size, which represented the diffraction of the $(200) /(110)$ plane.

$$
L_{h k l}=\frac{K \lambda}{\beta \cos \theta}
$$

(Equation 2)

\subsubsection{Thermogravimetric analysis (TGA)}

Thermal stability data were obtained by thermogravimetry by means of a Mettler-Toledo TGA 851 series (Columbus, $\mathrm{OH}$ ). The samples, with a mass of about $4 \mathrm{mg}$ were introduced in TGA Mettler-Toledo perforated alumina crucibles, with capacity of $70 \mu$. The samples were analysed in the temperature range of 25 to $800{ }^{\circ} \mathrm{C}$ with a heating rate of $10^{\circ} \mathrm{C} \cdot \mathrm{min}^{-1}$, under atmosphere of oxygen at a flow rate of $50 \mathrm{ml} \cdot \mathrm{min}^{-1}$. Experiments were repeated at least three times and the averages were considered as representative values.

\subsubsection{Dynamic-mechanical-thermal analysis (DMTA)}

Dynamic mechanical thermal analyses were conducted by the two-point bending mode in single cantilever clamping with $6 \mathrm{~mm}$ of effective length between clamps, by means of Mettler-Toledo DMA861e (Columbus, $\mathrm{OH}$ ). The displacement was checked before all the experiments. The deformation force was set at $0.1 \mathrm{~N}$. Experiments were carried out by heating from $35^{\circ} \mathrm{C}$ to 130 ${ }^{\circ} \mathrm{C}$ with isothermal steps of $2{ }^{\circ} \mathrm{C}$ at $1 \mathrm{~Hz}$ of frequency and the displacement amplitude set at 10 $\mu \mathrm{m}$. Analyses were performed at least three times to ensure reproducibility.

\subsubsection{Field emission scanning electron microscopy (FE-SEM)}

The matrix-fibre interface was analysed by means of a Zeiss Ultra 55 Field emission scanning electron microscope (Oberkochen, Germany) to determine the morphology of the cryofracture obtained by breaking the samples after their immersion into liquid $\mathrm{N}_{2}$ during $1 \mathrm{~min}$. The aged and non-aged samples were cut into small pieces and dried at $50^{\circ} \mathrm{C}$ in a vacuum oven for $24 \mathrm{~h}$ and then kept in desiccator during $48 \mathrm{~h}$ before FE-SEM sample preparation. The pieces were mounted on metal studs and sputter-coated with platinum during $10 \mathrm{~s}$ using a Leica EM MED020 high resolution sputter coater (Wetzlar, Germany). The analyses were performed at room temperature at a voltage of $3 \mathrm{kV}$.

\section{Results and discussion}

\subsection{Influence of fibre, coupling agent and temperature on water absorption capability of PLA/sisal biocomposites}

Table 1 shows the percentage of absorbed water at equilibrium $\left(M_{S}\right)$ for VPLA and biocomposites at the hydrothermal ageing temperatures $\left(T_{H A}\right)$ chosen for the study. VPLA attained a $\sim 1 \%$ of $M_{S}$, regardless the $T_{H A}$. Due to presence of abundant hydroxyl groups on the cellulose molecules of 
O. Gil-Castell, J. D. Badia, T. Kittikorn, E. Strömberg, M. Ek, S. Karlsson, A. Ribes-Greus. Impact of hydrothermal ageing on the thermal stability, morphology and viscoelastic performance of PLA/sisal biocomposites. Polymer Degradation and Stability 2016, 132; 87-96

the sisal fibre, liable to interact with water molecules [34], the biocomposites showed $M_{S}$ values from $3 \%$ to $10 \%$.

Table 1. Water saturation mass $(M S)$ for VPLA and composites at all $T_{H A}$.

\begin{tabular}{lllllll}
\hline \multirow{2}{*}{$M_{\boldsymbol{S}}(\boldsymbol{\%})$} & \multicolumn{7}{c}{$\boldsymbol{T}_{\boldsymbol{H A}}\left({ }^{\mathbf{}} \mathbf{C}\right)$} \\
\cline { 2 - 7 } & $\mathbf{6 0}$ & $\mathbf{6 5}$ & $\mathbf{7 0}$ & $\mathbf{7 5}$ & $\mathbf{8 0}$ & $\mathbf{8 5}$ \\
\hline VPLA & 1.1 & 1.2 & 0.8 & 0.9 & 1.1 & 1.1 \\
\hline PLA10 & 3.6 & 3.6 & 3.0 & 3.7 & 3.2 & 3.2 \\
\hline PLA20 & 6.3 & 6.3 & 6.1 & 7.1 & 6.1 & 6.2 \\
\hline PLA30 & 9.4 & 8.7 & 10.4 & 9.3 & 6.3 & 10.3 \\
\hline PLA10C & 4.9 & 5.1 & 4.2 & 3.9 & 2.3 & 3.0 \\
\hline PLA20C & 7.4 & 6.9 & 5.9 & 6.1 & 5.1 & 5.2 \\
\hline PLA30C & 8.3 & 8.0 & 7.6 & 8.1 & 7.7 & 9.0 \\
\hline
\end{tabular}

In order to assess the influence of fibre, coupling agent and ageing temperature, a statistical factorial analysis (SFA) was applied [35] [36]. Figure 1 shows that the amount of fibre was the most influent factor, followed by the presence of the coupling agent in the composite. However, the variation of temperature slightly modified the percentage of absorbed water at equilibrium $\left(M_{S}\right)$ by biocomposites and thus, was not considered for further analyses. Samples subjected to an accelerated hydrothermal ageing at $85{ }^{\circ} \mathrm{C}$ were therefore chosen to focus the study on the influence of fibre content and coupling agent.

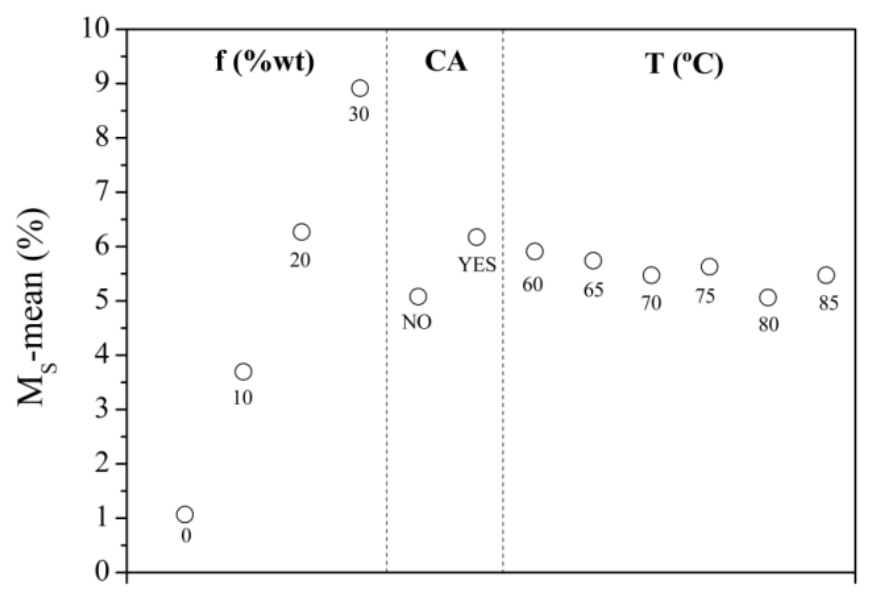

Figure 1. Main-effects plot of relations between fibre, coupling agent and hydrothermal ageing temperature for water saturation mass $(M S)$.

\subsection{Impact of hydrothermal ageing on thermal stability of PLA/sisal biocomposites}

Thermal stability was assessed by means of thermogravimetric analysis (TGA) in order to ascertain the state of chemical degradation in the biocomposites. Figure 2 shows the thermogravimetric (TG) and derivative thermogravimetric (DTG) curves for PLA/sisal biocomposites before and after the hydrothermal ageing. All curves showed a general weight-loss of 98-99\%, regardless the formulation of the biocomposites. They exhibited four differentiated weight-loss stages, in accordance with reported results for sisal fibre [37]. The first slight initial loss can be related with remnant water present in both the matrix and fibres [38]. Then, the second decomposition stage, from $222{ }^{\circ} \mathrm{C}$ to $315^{\circ} \mathrm{C}$, is assigned to the decomposition of hemicellulose. The third stage, from $315^{\circ} \mathrm{C}$ to $400{ }^{\circ} \mathrm{C}$, was caused by decomposition of both the PLA matrix and 
O. Gil-Castell, J. D. Badia, T. Kittikorn, E. Strömberg, M. Ek, S. Karlsson, A. Ribes-Greus. Impact of hydrothermal ageing on the thermal stability, morphology and viscoelastic performance of PLA/sisal biocomposites. Polymer Degradation and Stability 2016, 132; 87-96

cellulose, which peaks at $356^{\circ} \mathrm{C}$ and $325^{\circ} \mathrm{C}$ respectively, are often overlapped. Finally, the fourth weight-loss from $380{ }^{\circ} \mathrm{C}$ to $500{ }^{\circ} \mathrm{C}$ is related to the degradation of char formed during previous decomposition.
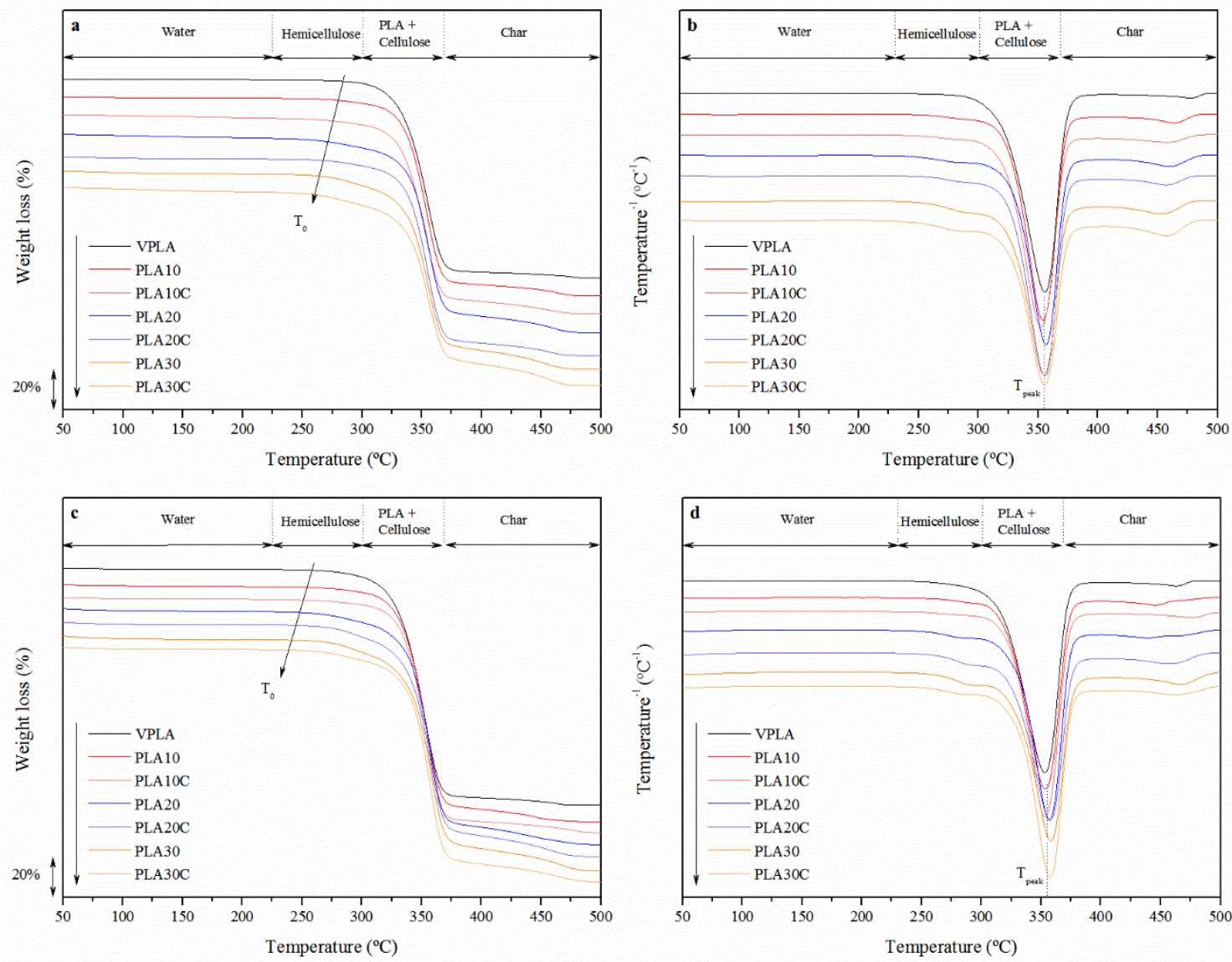

Figure 2. Decomposition TG (a) and DTG (b) curves prior to hydrothermal ageing and TG (c) and DTG (d) curves after hydrothermal ageing for VPLA and biocomposites.

The peak decomposition temperature $\left(T_{\text {peak }}\right)$ remained almost constant prior to and after hydrothermal ageing for all materials. The evolution of $T_{0}$, calculated as the temperature in which weight-loss was $5 \%$ is plotted in Figure 3. Before hydrothermal ageing, the presence of sisal induced lower $T_{0}$, due to its lower thermal stability, which resulted in a difference of $30{ }^{\circ} \mathrm{C}$ between VPLA $\left(315^{\circ} \mathrm{C}\right)$ and PLA30 $\left(285^{\circ} \mathrm{C}\right)$. The degradation of the hemicellulose seems to be responsible for this decrease. A decrease in the molecular weight of the PLA matrix during processing can also contribute to reduction of the onset degradation temperature [12]. Even though, $T_{0}$ was higher for biocomposites than for pure sisal fibre, attributed to protection of fibre by polymer matrix, according to Albano et al. [39]. The presence of coupling agent considerably reduced $T_{0}$ in all cases $\left(\sim 10\right.$ to $\left.20^{\circ} \mathrm{C}\right)$. This effect may be assigned to the reduction in molecular weight due to incorporation of dicumyl peroxide (DCP) followed by a maleic anhydride (MAH) branching reaction [12] [40]. 
O. Gil-Castell, J. D. Badia, T. Kittikorn, E. Strömberg, M. Ek, S. Karlsson, A. Ribes-Greus. Impact of hydrothermal ageing on the thermal stability, morphology and viscoelastic performance of PLA/sisal biocomposites. Polymer Degradation and Stability 2016, 132; 87-96

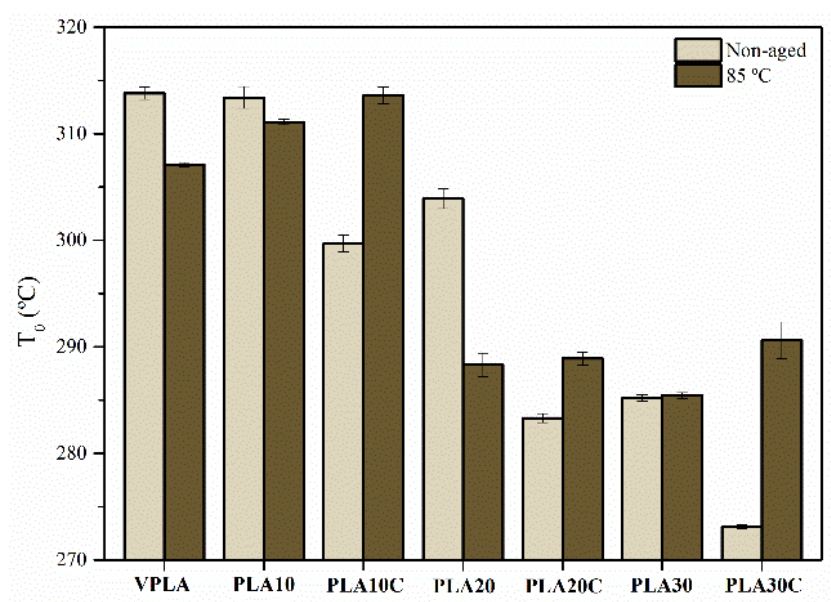

Figure 3. Evolution of the onset temperature $\left(T_{0}\right)$ prior to and after hydrothermal ageing at $85^{\circ} \mathrm{C}$ for VPLA and biocomposites.

After hydrothermal ageing, two different behaviours were observed. For a given non-coupled biocomposite, hydrolytic reactions may have degraded the fibre-matrix interface, promoting peeling and delamination, thus exposing sisal fibre to ambient environment, showing the subsequent general decrease in $T_{0}$. However, when coupling agent was added, an increment of $T_{0}$ was determined. Thus, though the presence of the coupling agent induced a reduction of thermal stability during processing, the biocomposites were more resilient to thermal decomposition after hydrothermal ageing. This might be explained by the presumable formation of crystals as a shell around sisal fibres [16], enhancing the fibre-matrix interface, as discussed in the next sections.

\subsection{Fibre-matrix interface: morphology of cryofractured biocomposites}

Fracture morphology before and after hydrothermal ageing was studied by field-emission scanning electron microscopy (FE-SEM). Figure 4 shows the micrographs of the cryofractured surface for VPLA and biocomposites before and after the hydrothermal ageing at $85^{\circ} \mathrm{C}$. For nonaged materials, VPLA showed an apparently smooth surface while for biocomposites, the presence of fibres provoked a completely different fracture surface characterised by pores, holes and fibre tails.

During processing, the suggested crystallisation might have induced internal rearrangements that confer more fragile performance, resulting in fibre detaching, holes and pores. Concerning coupled biocomposites, better adhesion between fibre and matrix seemed to take place, but holes and traces still appeared after fracture. 
O. Gil-Castell, J. D. Badia, T. Kittikorn, E. Strömberg, M. Ek, S. Karlsson, A. Ribes-Greus. Impact of hydrothermal ageing on the thermal stability, morphology and viscoelastic performance of PLA/sisal biocomposites. Polymer

Degradation and Stability 2016, 132; 87-96
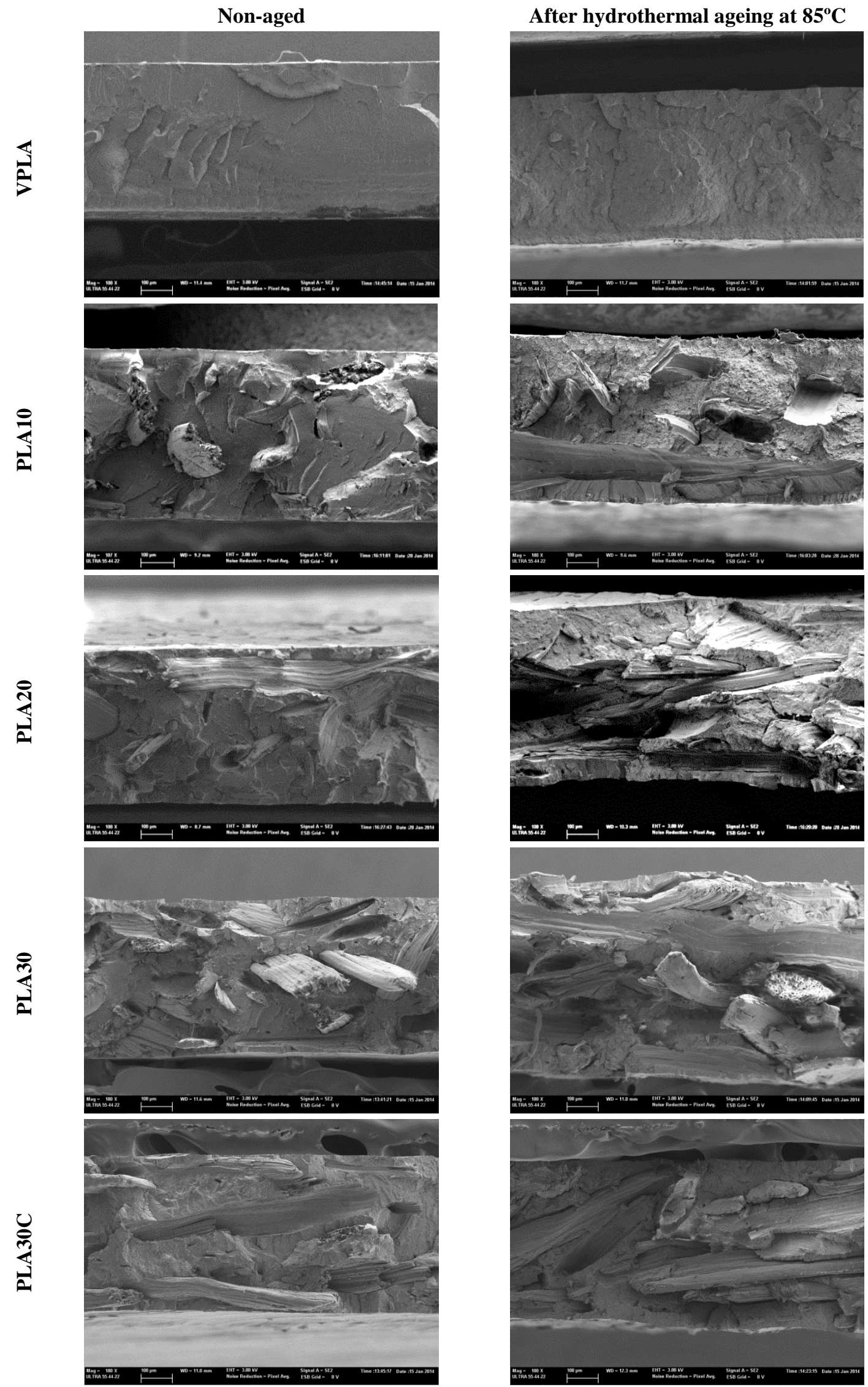

Figure 4. FE-SEM micrographs for VPLA and PLA/sisal biocomposites prior to and after hydrothermal ageing at 85 ${ }^{\circ} \mathrm{C}(3 \mathrm{kV}, 100 \times, 100 \mu \mathrm{m})$. 
O. Gil-Castell, J. D. Badia, T. Kittikorn, E. Strömberg, M. Ek, S. Karlsson, A. Ribes-Greus. Impact of hydrothermal ageing on the thermal stability, morphology and viscoelastic performance of PLA/sisal biocomposites. Polymer Degradation and Stability 2016, 132; 87-96

After hydrothermal ageing, PLA matrix showed a rougher texture in VPLA and biocomposites. This change in the polymeric texture are in agreement with the hypothesis of the crystallisation occurred during hydrothermal ageing. The increase in fibre dimensions caused by swelling may deteriorate the interface, influencing the mechanical properties as shown afterwards, and resulted in cracks and rifts around fibres. However, the presence of coupling agent contributed to reach better polymer/fibre interface. Figure 5 shows the detail of PLA30 and PLA30C for the sake of comparison. Prior to ageing, a small gap between fibre and matrix could be seen for PLA30, while a kind of polymeric covering of fibres by PLA matrix was found for PLA30C. After ageing, the separation of fibres and polymeric phase increased for PLA30. However, the presence of coupling agent in PLA30C seemed to reduce delamination.
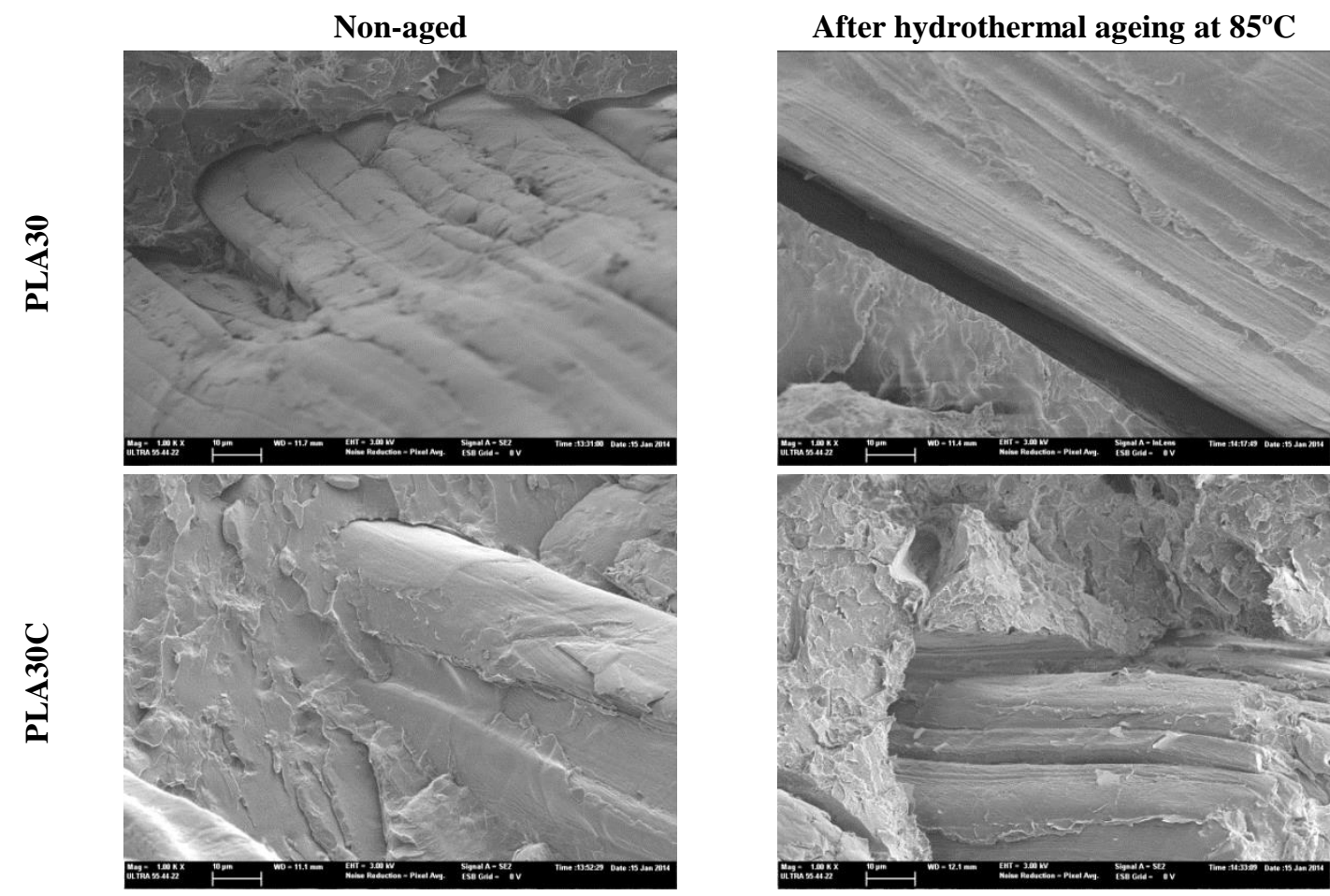

Figure 5. FE-SEM detail micrographs for PLA30 and PLA30C prior to and after hydrothermal ageing at $85^{\circ} \mathrm{C}(3 \mathrm{kV}$, $1000 \times, 10 \mu \mathrm{m})$.

\subsection{Development of crystallisation during hydrothermal ageing}

It has been suggested in previous sections that the influence of water in the polymer matrices in combination with the temperature effect and the presence of sisal fibres might be a consequence of microstructure change, and thus X-Ray diffraction was considered to counter-check results.

Figure 6 shows the diffraction patterns of VPLA and biocomposites prior to and after hydrothermal ageing at $85^{\circ} \mathrm{C}$. The crystallinity of PLA matrix can be found by the reflection peaks positioned at $16.8^{\circ}, 19.1^{\circ}$ and $22.6^{\circ}$, which represented the diffractions of (200)/(110), (203), (210) planes respectively [41]. Prior to the hydrothermal ageing, VPLA showed reflections at $16.8^{\circ}$ and $19.1^{\circ}$ related to typical PLA crystalline domains. Biocomposites also showed characteristic reflections of a semicrystalline microstructure, more intense when sisal fibre augmented. In addition, a wide reflection around $22.5^{\circ}$ was observed, which corresponded to the diffraction of the (002) plane of the sisal fibre, as described by M. Benítez-Guerrero et al. [42]. This reflection associated to sisal presumably overlapped the peak at $22.6^{\circ}$, characteristic of the PLA crystalline domains. After hydrothermal ageing, a general reduction of the wide flat signal 
O. Gil-Castell, J. D. Badia, T. Kittikorn, E. Strömberg, M. Ek, S. Karlsson, A. Ribes-Greus. Impact of hydrothermal ageing on the thermal stability, morphology and viscoelastic performance of PLA/sisal biocomposites. Polymer Degradation and Stability 2016, 132; 87-96

between $10^{\circ}$ and $30^{\circ}$ corresponding to the amorphous morphology of PLA, was shown. This reduction was compensated by the increase of the sharp peaks at $16.8^{\circ}$ and $19.1^{\circ}$, suggesting an increment in crystallinity in aged materials.

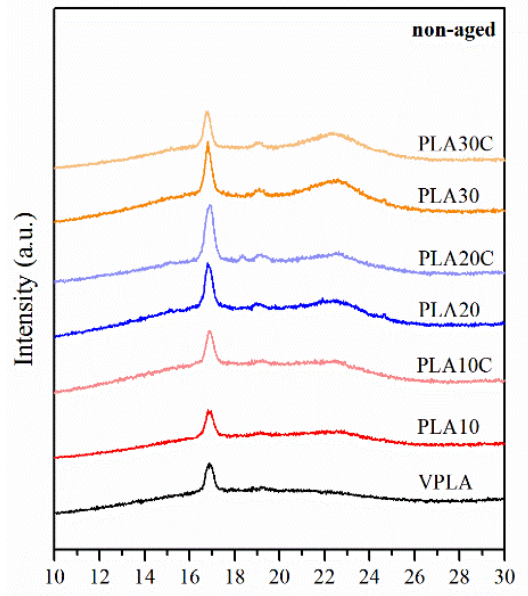

20

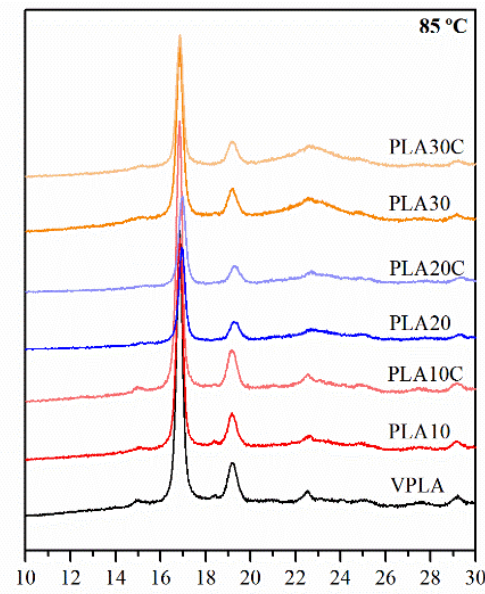

20

Figure 6. Diffraction patterns of VPLA and biocomposites prior to and after hydrothermal ageing at $85^{\circ} \mathrm{C}$.

Several studies demonstrated that a diffraction at $24.1^{\circ}$ corresponding to (016) plane is related to the presence of crystalline domains in PLA in the $\alpha$ mode [43] [44] [45]. Conversely, an absence of the peak at $24.1^{\circ}$ indicates that the structure of the crystalline domains of PLA are ordinated according to the $\alpha^{\prime}$ mode, which occasionally is corroborated by a reflection at $24.6^{\circ}$ [46]. The differences between the $\alpha^{\prime}$ and the $\alpha$ crystalline modes are mainly based on a slight rearrangement of the chain conformation and packing in the unit cell, especially related to the side groups, to achieve a more energy-favourable state, i.e. the reduction of unit cell dimension [44]. The transition from $\alpha^{\prime}$ to $\alpha$ form usually takes place by an increase of the crystallisation temperature $\left(T_{c} \geq 105^{\circ} \mathrm{C}\right)$ [47]. The phase composition determination in polymorphic polymers is typically evaluated from the ratio of the intensity of the reflections of one crystal mode to the sum of the heights of intensities of the reflections of all polymorphs. However, a precise estimation cannot be performed for PLA samples, as the two polymorphs have very similar profiles with slight differences, e.g. a small shift in peak position and/or appearance of very weak reflections [47]. Taking into account the complex differentiation of both polymorphs for PLA based materials a particular structure cannot be defined. Even so, the peak absence at $24.1^{\circ}$ suggested the presence of the $\alpha^{\prime}$ mode for all materials.

In order to evaluate the crystalline structure from X-Ray diffraction studies, the mean size of the crystalline domains $\left(L_{h k l}\right)$ was calculated from the peak at $16.8^{\circ}$, which represented the diffraction of (200)/(110) plane, according to Equation 2. Figure 7 shows the obtained results along with the crystallinity degree values obtained in a previous study by means of calorimetric analyses [12]. Accordingly, the crystallinity of these materials can be qualitative and quantitatively ascertained. Prior to hydrothermal ageing, greater crystallinity degree involving bigger crystal size was found for biocomposites. During processing, the presence of sisal fibres promoted the formation of bigger crystalline domains than those found for VPLA. After hydrothermal ageing at $85^{\circ} \mathrm{C}$, the crystallinity degree grew in all cases. However, the generation of the new crystalline populations was not directly related with a mean size increment. This fact can be understood in terms of the competitive behaviours of nucleation and growth of crystalline domains. VPLA and PLA/sisal biocomposites with low fibre content showed an increase of crystal size, assignable to 
O. Gil-Castell, J. D. Badia, T. Kittikorn, E. Strömberg, M. Ek, S. Karlsson, A. Ribes-Greus. Impact of hydrothermal ageing on the thermal stability, morphology and viscoelastic performance of PLA/sisal biocomposites. Polymer Degradation and Stability 2016, 132; 87-96

a more relevant growth of crystals. In contrast, the increment of $L_{(200 / 110)}$ for biocomposites was lower as fibre content increased. Concretely, the crystalline size for PLA30 and PLA30C almost remained constant after hydrothermal ageing, which may be related to a more prominent nucleation process. This fact was in line with the observation of transcrystalline regions throughout the fibres which implies the generation of small crystalline domains around fibres, perpendicular to the fibre surface [48]. Actually, natural fibres as jute or sisal into a PLA matrix are known to generate a particular oriented microstructure, as demonstrated by Le Duigou et al. [16]. Summing up, hydrothermal ageing promoted in composites the transcrystallisation phenomenon, more perceptible as fibre content increased.

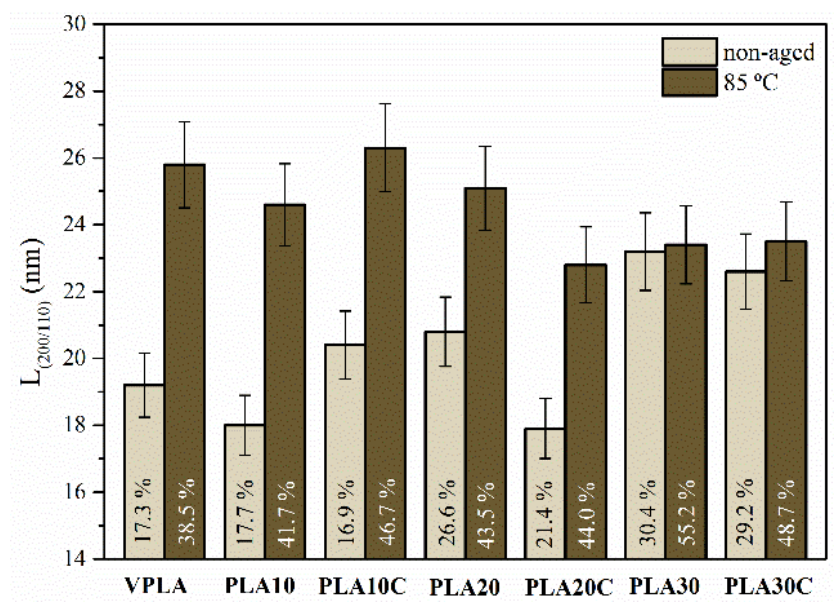

Figure 7. Mean size of the crystalline domains $\left(L_{(200 / 110)}\right)$ for VPLA and biocomposites prior to and after hydrothermal ageing at $85^{\circ} \mathrm{C}$. Percentage values gathered in bars correspond to the crystallinity degree $\left(X_{c}\right)$, as obtained from calorimetric analyses in a previous study [12].

\subsection{Impact of hydrothermal ageing on dampening, storage modulus and fibre effectiveness}

Dynamic mechanic thermal analysis (DMTA) is a widely used technique for investigating the viscoelastic behaviour of polymeric materials, giving information about the stiffness and damping characteristics of the material by means of the storage modulus $\left(E^{\prime}\right)$, the loss modulus $\left(E^{\prime \prime}\right)$ and the tangent of the out-of-phase angle delta $(\tan \delta)$ [49]. The determination of those properties over a range of temperatures is important in polymer and composite characterisation prior to and after ageing and degradation tests [50] [51] [52] [53] [54].

Table 2. Glass-rubber relaxation temperature $\left(T_{G R}\right)$ for VPLA and biocomposites prior to and after hydrothermal ageing at $85^{\circ} \mathrm{C}$.

\begin{tabular}{cccccccc}
\hline$T_{G R}\left({ }^{\circ} \mathrm{C}\right)$ & VPLA & PLA10 & PLA20 & PLA30 & PLA10C & PLA20C & PLA30C \\
\hline Non-aged & 62.61 & 63.37 & 63.54 & 63.70 & 63.63 & 63.58 & 63.88 \\
\hline Hydrothermal ageing at $85^{\circ} \mathrm{C}$ & 74.15 & 72.27 & 72.12 & 71.95 & 72.56 & 71.87 & 73.87 \\
\hline
\end{tabular}

The dampening gives information about the internal friction of the biocomposites and consequently would be influenced by the molecular motion in the interface, which can be studied in terms of tangent of delta ( $\tan \delta$, i.e. $\left.E^{\prime \prime} / E^{\prime}\right)$ [55]. In the Figure 8a, the $\tan \delta$ is represented as a function of temperature for VPLA, PLA30 and PLA30C before and after hydrothermal ageing. The peak in the dampening is known to take place within the glass transition and its maximum is often recorded as the glass-rubber relaxation temperature $\left(T_{G R}\right)$ [55]. Temperature values of $\tan \delta$ peak are gathered in Table 2. Non-aged materials showed similar $T_{G R}$. However, after hydrothermal ageing, the value shifted to temperatures around $\sim 10{ }^{\circ} \mathrm{C}$ higher for all cases. This 
O. Gil-Castell, J. D. Badia, T. Kittikorn, E. Strömberg, M. Ek, S. Karlsson, A. Ribes-Greus. Impact of hydrothermal ageing on the thermal stability, morphology and viscoelastic performance of PLA/sisal biocomposites. Polymer Degradation and Stability 2016, 132; 87-96

increment was related to the crystalline phase formation during ageing, which hindered the movement of amorphous polymer chains. Moreover, some peaks could be observed after glass transition. Internal chain rearrangements previous to the polymer cold-crystallisation, connected with the interactions between fibre and PLA matrix might be the cause of the appearance of this atypical behaviour. Figure $\mathbf{8 b}$ shows the peak heights of $\tan \delta$ as a function of fibre content and coupling agent prior to and after hydrothermal ageing at $85^{\circ} \mathrm{C}$. This parameter is usually considered as a useful indicator of the dampening behaviour. Due to processing, a reduction of both the height and the broadening of the relaxation was observed in the presence of sisal. This effect was greater with increasing the fibre content. As suggested by Pothan et al. [56], for a composite with a low fibre ratio, the polymer chains are relatively free to move. However, when the fibre content is increased, the mobility of the polymer chains is reduced, hindered by the reinforcement and crystallinity formed during the preparation of composites. After hydrothermal ageing, the profiles of tan $\delta$ showed a peak about $60 \%$ lower and considerably wider for all studied compositions. All materials, including VPLA, showed equivalent constraints of chain motion of the amorphous phase due to the increased crystallinity during ageing.
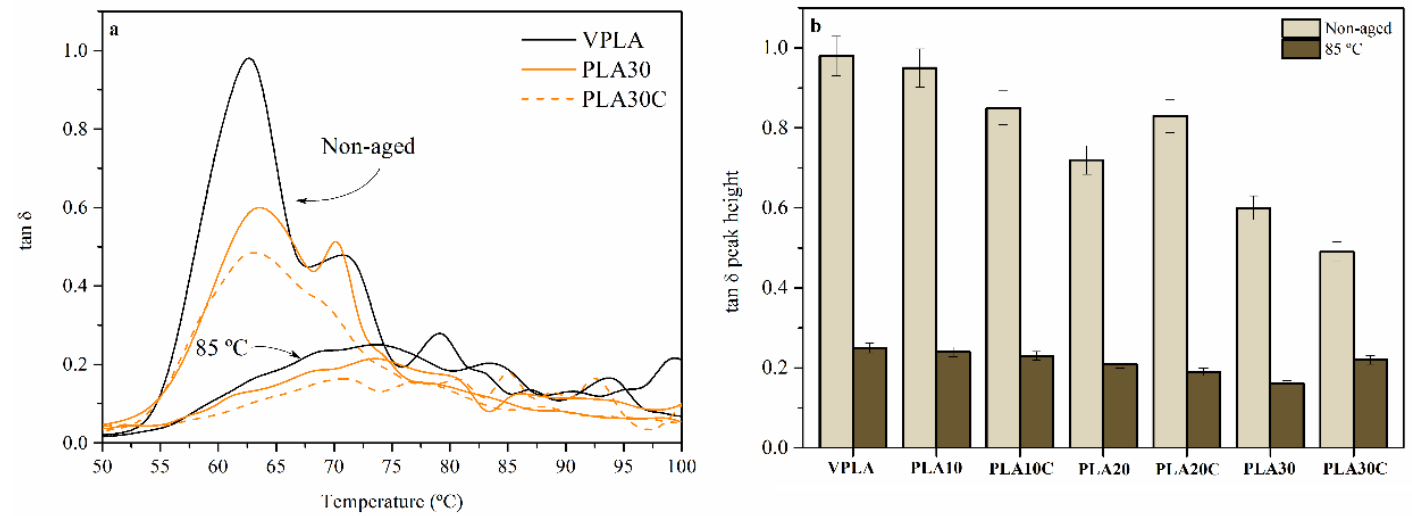

Figure 8. (a) Tangent delta $\left(\tan \delta\right.$ ) as a function of temperature prior to and after hydrothermal ageing at $85{ }^{\circ} \mathrm{C}$ for VPLA, PLA30 and PLA30C; (b) tan $\delta$ peak height as a function of fibre content for VPLA and composites prior to and after hydrothermal ageing at $85^{\circ} \mathrm{C}$.

Figure 9 shows the evolution of the storage modulus $\left(E^{\prime}\right)$ from the glassy to the rubbery state for all the biocomposites before and after the hydrothermal ageing. VPLA exhibited a similar behaviour as in literature, showing an $E^{\prime}$ around $2200 \mathrm{MPa}$ [4] [57] [58]. Regarding to biocomposites, prior to hydrothermal ageing, the crystallisation around sisal induced a reduction of mobility and deformation of the matrix. The presence of coupling agent improved the fibrematrix interface. In agreement with literature, it caused an effective stress transfer from matrix to fibres through the crystalline domains [55] [59] [60] [61] [62]. Along the DMTA experiment, a drastic drop of $E^{\prime}$ was observed within the glass-rubber relaxation. Afterwards, $E^{\prime}$ started to increase again around $80^{\circ} \mathrm{C}$ which confirmed the typical effect of cold-crystallisation [4] [12]. This change in trend occurred at lower temperatures as the fibre content increased, reaching higher $E^{\prime}$ once the cold-crystallisation was completed.

After hydrothermal ageing, the glass-rubber relaxation turned into a smoother transition and the cold-crystallisation phenomenon disappeared, in agreement with the complete crystalline development suggested in previous sections. Two differentiated behaviours were found above and below the glass-rubber relaxation temperature $T_{G R}$. On the one hand, below the $T_{G R}$, the deterioration of the fibre-matrix interface caused by water resulted in lower storage modulus for the biocomposites. However, above the $T_{G R}$, the crystalline structure formed during the 
O. Gil-Castell, J. D. Badia, T. Kittikorn, E. Strömberg, M. Ek, S. Karlsson, A. Ribes-Greus. Impact of hydrothermal ageing on the thermal stability, morphology and viscoelastic performance of PLA/sisal biocomposites. Polymer Degradation and Stability 2016, 132; 87-96

hydrothermal degradation promoted a higher storage modulus for composites in the rubbery state. This effect was higher for coupled biocomposites.
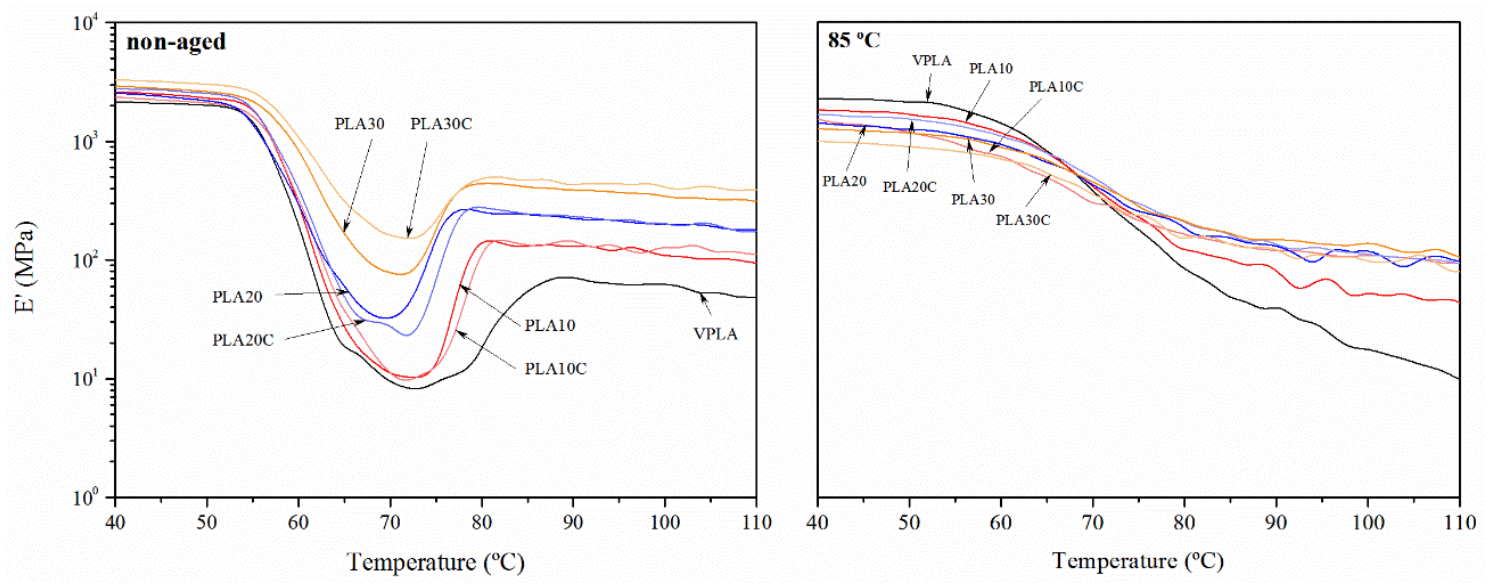

Figure 9. Storage modulus $\left(E^{\prime}\right)$ as a function of temperature for VPLA and composites prior to (left) and after hydrothermal ageing (right).

Figure 10 shows the $E^{\prime}$ values taken at $40{ }^{\circ} \mathrm{C}$ in the glassy state with the purpose of quantifying the effects of fibre and coupling agent as well as the effect of hydrothermal ageing. For non-aged samples, $E^{\prime}$ increased by $20 \%$ (2200 to $3000 \mathrm{MPa}$ ) from VPLA to PLA30. For a given fibre percentage, coupling agent generally promoted an increase in $E^{\prime}$, greater when fibre content increased, reaching the highest value for PLA30C (3300 MPa). After hydrothermal ageing at 85 ${ }^{\circ} \mathrm{C}, E^{\prime}$ slightly increased for VPLA (2200 to $2800 \mathrm{MPa}$ ) while it decreased for biocomposites. In general, the presence of sisal fibre reduced $E^{\prime}$. This reduction was greater the higher the fibre content was. A reduction from 2800 to $600 \mathrm{MPa}$ between VPLA and PLA30 was found. The coupling agent always contributed to minimise the effect of hydrothermal ageing around $\sim 10 \%$.

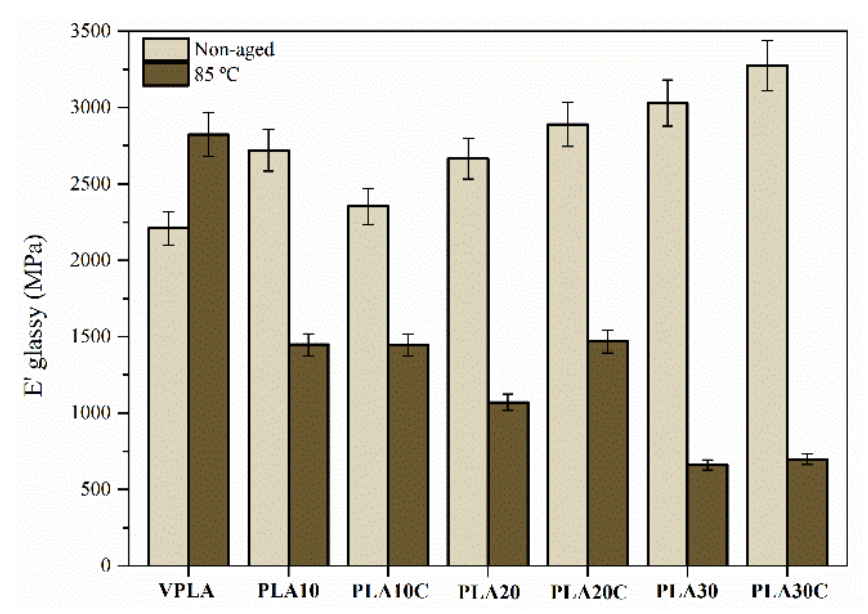

Figure 10. Storage modulus $\left(E^{\prime}\right)$ in the glassy state as a function of fibre content for VPLA and composites prior to and after hydrothermal ageing at $85^{\circ} \mathrm{C}$.

Finally, the mechanical fibre effectiveness, i.e. $M F E$, was calculated according to Equation 3 [56] [63], where $E_{g}^{\prime}$ and $E_{r}^{\prime}$ are the storage modulus values in the glassy and rubbery region respectively. In general terms, the higher the value of the constant MFE is, the higher the effectiveness of the filler is considered. 
O. Gil-Castell, J. D. Badia, T. Kittikorn, E. Strömberg, M. Ek, S. Karlsson, A. Ribes-Greus. Impact of hydrothermal ageing on the thermal stability, morphology and viscoelastic performance of PLA/sisal biocomposites. Polymer Degradation and Stability 2016, 132; 87-96

$$
M F E=1-\frac{\left(E_{g}^{\prime} / E_{r}^{\prime}\right)_{\text {comp }}}{\left(E_{g}^{\prime} / E_{r}^{\prime}\right)_{\text {resin }}} \quad(\text { Equation 3) }
$$

Figure 11 shows the values of the $M F E$, taking the measured $E^{\prime}$ values at $40{ }^{\circ} \mathrm{C}$ and $100{ }^{\circ} \mathrm{C}$ as $E_{g}^{\prime}$ and $E_{r}^{\prime}$ respectively. Prior to hydrothermal ageing, the effectiveness of the filler was significantly higher when the sisal content increased, in agreement with other reports [59] [60] [61]. The most effective fibre percentage was always $30 \%$ by weight, which revealed active stress transfer between fibre and matrix through the crystalline phase formed both during processing and the DMTA experiment. After hydrothermal ageing, an increase of $M F E$ was found for all cases, as a result of the induced crystalline formation around fibres in the so-called transcrystalline region. The influence of coupling agent could be perceived at low fibre contents, while it was negligible for biocomposites with fibre content higher than $20 \%$ by weight.

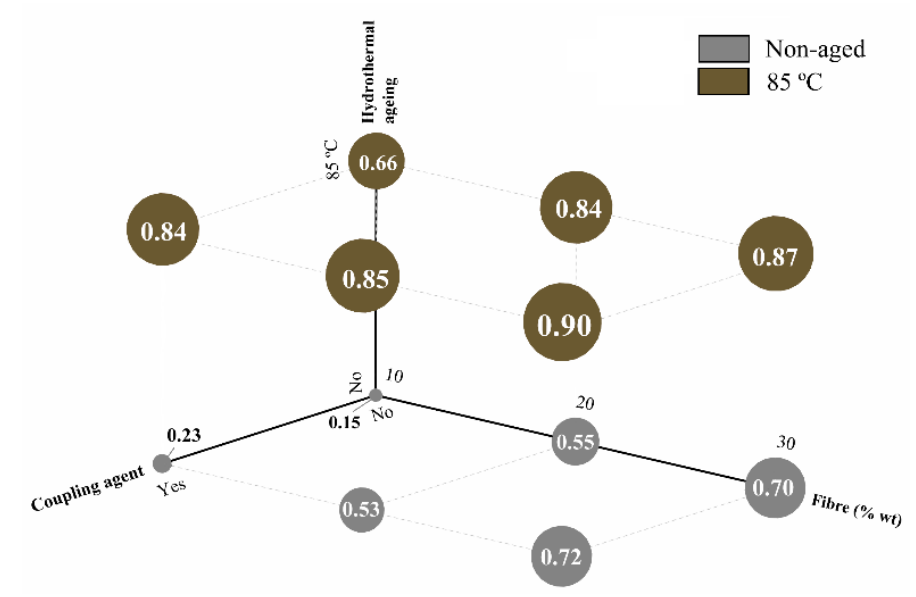

Figure 11. Values of the $M F E$ as obtained by Equation 3, for VPLA and composites prior to and after hydrothermal ageing at $85^{\circ} \mathrm{C}$.

\section{Conclusions}

An accelerated hydrothermal ageing test was a suitable procedure to evaluate the combined influence of water and temperature on the morphology of PLA/sisal biocomposites, and the subsequent effects on the thermal and viscoelastic stability of the materials.

After the preparation of biocomposites, the sisal fibre promoted crystallisation which altered the viscoelastic properties, increasing the storage modulus. However, lower thermal stability was established for biocomposites. The presence of coupling agent slightly affected the crystalline formation, increased the storage modulus and displaced the thermo-decomposition process towards higher temperatures.

Hydrothermal ageing boosted crystallisation for all studied biocomposites, both in terms of crystalline degree and mean size of crystals. It also provoked a general reduction of the storage moduli of biocomposites, along with a decrease of the dampening performance, due to chemical degradation, therefore showing more fragile behaviour evidencing pores and cracks. The mechanical effectiveness of the fibres in aged biocomposites was improved by the addition of fibres. Results showed that PLA/sisal biocomposites with coupling agent were resilient to hydrothermal ageing. 
O. Gil-Castell, J. D. Badia, T. Kittikorn, E. Strömberg, M. Ek, S. Karlsson, A. Ribes-Greus. Impact of hydrothermal ageing on the thermal stability, morphology and viscoelastic performance of PLA/sisal biocomposites. Polymer Degradation and Stability 2016, 132; 87-96

\section{Acknowledgements}

The authors would like to acknowledge the Spanish Ministry of Economy and Competitiveness, through the Research Project ENE2014-53734-C2-1-R and UPOV13-3E-1947. The Spanish Ministry of Education, Culture and Sports is also thanked for the predoctoral FPU grant of O. GilCastell (FPU13/01916). Generalitat Valenciana is thanked for the APOSTD14/041 program for J.D. Badia. The Chilean Government is thanked for the 13CEI2-21839 project.Tthe financial support given by the Prince of Songkla University and KTH Royal Institute of Technology is gratefully acknowledged.

\section{References}

[1] Mapleston P. Environmentally degrading: Bioplastics in Europe (part 2). Plastics Engineering Europe Spring, pg. 24-29, 2006.

[2] Mapleston P. Following the green line: Bioplastics in Europe. Plastics Engineering Europe Winter, pg. 14-19, 2005.

[3] Bax B, Müssig J. Impact and tensile properties of PLA/cordenka and PLA/flax composites. Composites Science and Technology, 2008; 68:1601-1607.

[4] Oksman K, Skrifvars M, Selin JF. Natural fibres as reinforcement in polylactic acid (PLA) composites. Composites Science Technology, 2003; 63:1317-24.

[5] Yew GH, Mohd Yusof AM, Mohd Ishak ZA, et al. Water absorption and enzymatic degradation of poly(lactic acid)/rice starch composites. Polymer Degradation and Stability, 2005; 90:488-500.

[6] Huda MS, Drzal LT, Mohanty AK, et al. Chopped glass and recycled newspaper as reinforcement fibres in injection molded poly(lactic acid) (PLA) composites: a comparative study. Composites Science and Technology, 2006; 66:1813-1824.

[7] Hu R, Lim JK. Fabrication and mechanical properties of completely biodegradable hemp fiber reinforced polylactic acid composites. Journal of Composites Materials, 2007; 41:1655-1669.

[8] Masud SH, Lawrence TD, Manjusri M. A study on biocomposites from recycled newspaper fibre and poly(lactic acid). Industrial and Engineering Chemical Research, 2005; 44:5593-5601.

[9] Smita M, Sushil KV, Sanjay KN. Dynamic mechanical and thermal properties of MAPE treated jute/HDPE composites. Composites Science and Technology, 2006; 66:538-547.

[10] Corrales F, Vilaseca F, Llop M, Giromes J, Mendez JA, Mutje P. Chemical modification of jute fibres for the production of green-composites. Journal of Hazardous Materials, 2007; 44:730-735.

[11] García M, Garmendia I, García J. Influence of natural fiber type in eco-composites. Journal of Applied Polymer Science,2008; 107:2994-3004.

[12] Gil-Castell O, Badia JD, Kittikorn T, Strömberg E, Martínez-Felipe A, Ek M, Karlsson S, Ribes-Greus A. Hydrothermal ageing of polylactide/sisal biocomposites. Studies of water absorption behaviour and PhysicoChemical performance, Polymer Degradation and Stability, 2014;108:212-222.

[13] Ray D, Sarkar BK, Rana AK, Bose N. The mechanical properties of vinyl ester resin matrix composites reinforced with alkali-treated jute fibres. Composites: Part A, 2001; 32:119-127.

[14] Stark N. Influence of moisture absorption on mechanical properties of wood flour-polypropylene composites. Journal of Thermoplastic Composite Materials, 2001; 14:421-432.

[15] Marcovich NE, Reboredo MM, Aranguren MI. Dependence of the mechanical properties of wood flour-polymer composites on the moisture content. Journal of Applied Science, 1998; 68:2069-2076.

[16] Le Duigou A, Davies P, Baley C. Interfacial bonding of Flax fibre/Poly(L-lactide) bio-composites. Composites Science and Technology, 2010; 70:231-239.

[17] Rangaraj SV, Smith L. Effects of moisture on the durability of a wood/thermoplastic composite. Journal of Thermoplastic Composite Materials, 2000; 13(3):140-161.

[18] Dhakal HN, Zhang ZY, Richardson MOW. Effect of water absorption on the mechanical properties of hemp fibre reinforced unsaturated polyester composites. Composites Science and Technology, 2007; 67(7-8):16741683.

[19] HS Kim, HJ Kim. Enhanced hydrolysis resistance of biodegradable polymers and bio-composites. Polymer Degradation and Stability, 2008; 93:1544-1553. 
O. Gil-Castell, J. D. Badia, T. Kittikorn, E. Strömberg, M. Ek, S. Karlsson, A. Ribes-Greus. Impact of hydrothermal ageing on the thermal stability, morphology and viscoelastic performance of PLA/sisal biocomposites. Polymer Degradation and Stability 2016, 132; 87-96

[20] Le Duigou A, Davies P, Baley C. Seawater ageing of flax/poly(lactic acid) biocomposites. Polymer Degradation and Stability, 2009; 94:1151-1162.

[21] Quan H, Li Z, Yang M, Huang R. On transcrystallinity in semi-crystalline polymer composites. Composites Science and Technology, 2005; 65(7-8):999-1021.

[22] Lu JZ, Wu Q, McNann HS. Chemical coupling in wood fiber and polymer composites: a review of coupling substances and treatment. Wood and Fiber Science, 2000; 32(1):88-104.

[23] Nabi Saheb D, Jog JP. Natural fiber polymer composites: a review. Advanced Polymer Technology, 1999; 18(4):351-363.

[24] Rozman HD, Lee MH, Kumar RN, Abusanag A, Mohd Ishak ZA. The effect of chemical modification of rice husk with glycidyl methacrylate on the mechanical and physical properties of rice husk-polystyrene composites, Journal of Wood Chemistry and Technology, 2000; 20(1):93-109.

[25] Gaylord NG, Mehta R. Peroxide-catalyzed grafting of maleic anhydride onto molten polyethylene in the presence of polar organic compounds, Journal of Polymer Science Part A: Polymer Chemistry, 1998; 26:1189-1198.

[26] Kim SJ, Shin BS, Hong JL, Cho WJ, Ha CS. Reactive compatibilization of the PBT/EVA blend by maleic anhydride. Polymer, 2001; 42:4073-4080.

[27] Beg MDH, Pickering KL. Accelerated weathering of unbleached and bleached kraft wood fibre reinforced polypropylene composites. Polymer Degradation and Stability, 2008; 93:1939-1946.

[28] Berthé V, Ferry L, Bénéze t JC, Bergeret A. Ageing of different biodegradable polyesters blends mechanical and hygrothermal behavior. Polymer Degradation and Stability, 2010; 95:262-269.

[29] Badia JD, Santonja-Blasco L, Martínez-Felipe A, Ribes-Greus A. Hygrothermal ageing of reprocessed polylactide. Polymer Degradation and Stability 2012;97(10):1881-1890.

[30] Badia JD, Kittikorn T, Strömberg E, Santonja-Blasco L, Martínez-Felipe A, Ribes-Greus A, Ek M, Karlsson S. Water absorption and hydrothermal performance of PHBV/sisal biocomposites. Polymer Degradation and Stability 2014;108:166-174.

[31] Kittikorn T. Tuning the long-term properties to control biodegradationby surface modifications of agricultural fibres in biocomposites. ISBN:978-91-7501-677-1. Ph.D. Thesis. Kungliga Tekniska Högskolan, 2013.

[32] ISO 291. Plastics. Standard atmospheres for conditioning and testing; 1997.

[33] ISO 62. Plastics. Determination of water absorption; 2008.

[34] Bismarck A, Askargorta IA, Springer J, Lampke T, Wielage B, Stamboulis A. Surface characterization of flax, hemp and cellulose fibres; surface properties and the water uptake behaviour. Polymer Composites, 2002; 23:872-894.

[35] Badia JD, Strömberg E, Ribes-Greus A, Karlsson S. Assessing the MALDI-TOF MS sample preparation procedure to analyze the influence of thermo-oxidative ageing and thermo-mechanical degradation on poly(lactide). European Polymer Journal, 2011; 47:1416-1428.

[36] Badia JD, Strömberg E, Ribes-Greus A, Karlsson S. A statistical design of experiments for optimizing the MALDI-TOF-MS sample preparation of polymers., An application in the assessment of the thermo-mechanical degradation mechanisms of poly (ethylene terephtalate). Analytica Chimica Acta, 2011; 692:85-95.

[37] Martin AR, Martins MA, da Silva ORRF, Mattoso LHC. Studies on the thermal properties of sisal fiber and its constituents. Thermochimica Acta, 2010; 506:14-19.

[38] Fairbridge C, Ross RA, Sood SP. A kinetic and surface study of the thermal decomposition of cellulose powder in inert and oxidizing atmospheres. Journal of Applied Polymer Science, 1978; 22(2):497-510.

[39] Albano C, González J, Ichazo M, Kaiser D. Thermal stability of blends of polyolefins and sisal fiber. Polymer Degradation and Stability, 1999; 66:179-190.

[40] Hwang SW, Lee SB, Lee CK, Lee JY, Shim JK, Selke SEM, Soto-Valdez H, Matuana L, Rubino M, Auras R. Grafting of maleic anhydride on poly(L-lactic acid). Effects on physical and mechanical properties. Polymer Testing, 2012; 31:333-344.

[41] Song Y, Tashiro K, Xu D, Liu J, Bin Y. Crystallization behavior of poly(lactic acid)/microfibrillated cellulose composite. Polymer, 2013; 54:3417-3425.

[42] Benítez-Guerrero M, López-Beceiro J, Sánchez-Jiménez PE, Pascual-Cosp J. Comparison of thermal behavior of natural and hot-washed sisal fibers based on their main components: Cellulose, xylan and lignin.TG-FTIR analysis of volatile products, Thermochimica Acta, 2014; 581:70-86.

[43] Zhang J, Tashiro K, Tsuji H, Domb AJ. Disorder-to-order phase transition and multiple melting behavior of poly(l-lactide) investigated by simultaneous measurements of WAXD and DSC. Macromolecules, 2008; 41(4):1352-1357. 
O. Gil-Castell, J. D. Badia, T. Kittikorn, E. Strömberg, M. Ek, S. Karlsson, A. Ribes-Greus. Impact of hydrothermal ageing on the thermal stability, morphology and viscoelastic performance of PLA/sisal biocomposites. Polymer Degradation and Stability 2016, 132; 87-96

[44] Pan P, Zhu B, Kai W, Dong T, Inoue Y. Polymorphic transition in disordered poly(l-lactide) crystals induced by annealing at elevated temperatures. Macromolecules, 2008; 41(12):4296-4304.

[45] Pan P, Kai W, Zhu B, Dong T, Inoue Y. Polymorphous crystallization and multiple melting behavior of poly(1lactide): molecular weight dependence. Macromolecules, 2007; 40(19):6898-6905.

[46] Miyata T, Masuko T. Morphology of poly(-lactide) solution-grown crystals. Polymer, 1997;38(16):4003-4009.

[47] Cocca M, Di Lorenzo ML, Malinconico M, Frezza V. Influence of crystal polymorphism on mechanical and barrier properties of poly(L-lactic acid). European Polymer Journal, 2011; 47:1073-1080.

[48] Wang Y, Tong B, Hou S, Li M, Shen C. Transcrystallization behavior at the poly(lactic acid)/sisal fibre biocomposite interface. Composites Part A: Applied Science and Manufacturing, 2011; 42(1)66-74.

[49] Badia JD, Santonja-Blasco L, Martínez-Felipe A, Ribes-Greus A. 2015, Dynamic Mechanical Thermal Analysis of Polymer Blends. Thomas S, Grohens Y, Jyotishkumar, ed., Characterization of Polymer Blends, Volume 1: Miscibility, Morphology and Interfacesv, Wiley-VCH, Weinheim, 365-392.

[50] O. Gil-Castell O, Badia JD, Teruel-Juanes R, Rodriguez I, Meseguer F, Ribes-Greus A. Novel silicon microparticles to improve sunlight stability of raw polypropylene. European Polymer Journal, 2015;70:247-261.

[51] Badia JD, Strömberg E, Karlsson S, Ribes-Greus A. Material valorisation of amorphous polylactide. influence of thermo-mechanical degradation on the morphology, segmental dynamics, thermal and mechanical performance. Polymer Degradation and Stability 2012, 97(4):670-678.

[52] Badia JD, Strömberg E, Karlsson S, Ribes-Greus A. The role of crystalline, mobile amorphous and rigid amorphous fractions in the performance of recycled poly (ethylene terephthalate) (PET). Polymer Degradation and Stability 2012;97(1):98-107.

[53] Santonja-Blasco L, Moriana R, Badía JD, Ribes-Greus A. Thermal analysis applied to the characterization of degradation in soil of polylactide: I. calorimetric and viscoelastic analyses. Polymer Degradation and Stability 2010;95(11):2192-2199.

[54] Badía JD, Vilaplana F, Karlsson S, Ribes-Greus A. Thermal analysis as a quality tool for assessing the influence of thermo-mechanical degradation on recycled poly(ethylene terephthalate). Polymer Testing 2009; 28(2):16975.

[55] Baghaei B, Skirfvars M, Berglin L. Manufacture and characterisation of thermoplastic composites made from PLA/hemp co-wrapped hybrid yarn prepregs. Composites: Part A, 2013; 50:93-101.

[56] Pothan LA, Oommen Z, Thomas S. Dynamic mechanical analysis of banana fiber reinforced composites. Composites Science and Technology, 2003; 63:283-293.

[57] Kowalczyk M, Piorkowska E, Kukpinski P, Pracella M. Mechanical and thermal properties of PLA composites with cellulose nanofibers and standard size fibers. Composites: Part A, 2011;42:1509-1514.

[58] Piekarska K, Sowinski P, Piorkowska E, Haque MdM-UI, Pracella M. Structure and properties of hybrid PLA nanocomposites with inorganic nanofillers and cellulose fibers. Composites: Part A, 2016;82:34-41.

[59] Huda MS, Drzal LT, Misra M, Mohanty AK, Williams K, Mielewski DF. A study on biocomposites from recycled newspaper fiber and poly(lactic acid). Industrial \& Engineering Chemistry Research, 2005; 44(15):5593-5601.

[60] Zhang Q, Shi L, Nie J, Wang H, Yang D. Study on poly(lactic acid)/natural fibers composites. Journal of Applied Polymer Science, 2012; 125(S2):E526-E533.

[61] Majhi SK, Nayak SK, Mohanty S, Unnikrishnan L. Mechanical and fracture behaviour of banana fiber reinforced polylactic acid biocomposites. International Journal of Plastics Technology, 2010; 14:(1)57-75.

[62] Cheung HY, Lau KT, Tao XM, Hui D. A potential material for tissue engineering: Silkworm silk/PLA biocomposite. Composites: Part B, 2008; 39:1026-1033.

[63] Tan JK, Kitano T, Hatakeyama T. Crystallisation of carbon fiber reinforced polypropylene. Journal of Materials Science, 1990; 25:3380-3384. 
O. Gil-Castell, J. D. Badia, T. Kittikorn, E. Strömberg, M. Ek, S. Karlsson, A. Ribes-Greus. Impact of hydrothermal ageing on the thermal stability, morphology and viscoelastic performance of PLA/sisal biocomposites. Polymer

Degradation and Stability 2016, 132; 87-96

\section{ANNEX. OPEN-ACCESS POLICIES}

Search - Publisher copyright policies \& self-archiving

English | Español | Magyar | Português

One journal found when searched for: 0141-3910

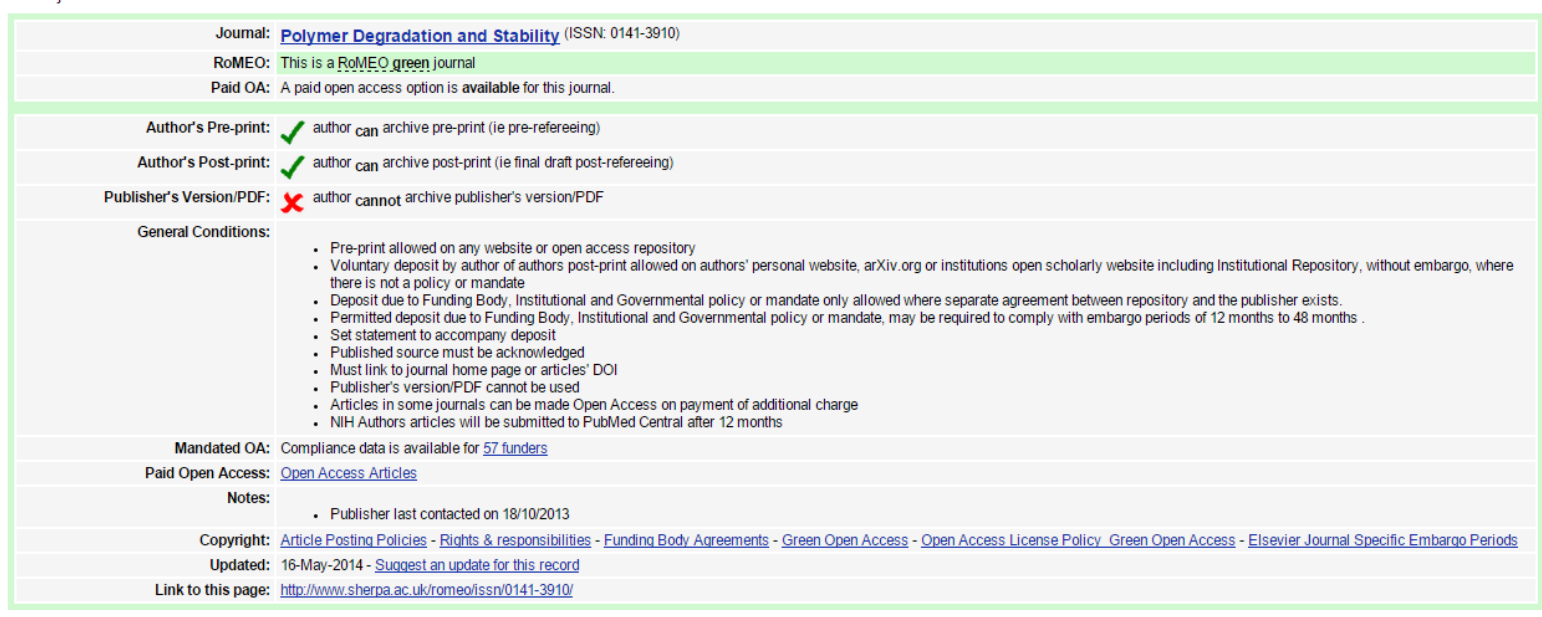

